\title{
HOW DO ANIMALS SPEND THE WINTER? A FINNISH STUDY ON THE USE OF VEE HEURISTICS IN A BIOLOGY UNIT FOR EIGHTH GRADERS
}

Sirpa Kärkkäinen

University of Eastern Finland, Joensuu, Finland

E-mail: sirpa.a.karkkainen@uef.fi

\begin{abstract}
The purpose of this study was to describe the eighth graders' (N=92) biology learning process and the use of Vee heuristics in six Finnish secondary school classes (age 13-14 years). The teaching unit "How do animals spend the winter?" had an inquiry-based approach by using Vee heuristics. Part of the learning took place in the local Science museum. In this study, Vee heuristics consisted of ten questions related to three different phases; the planning, implementation and evaluation phases. In the planning phase, pupils were interested in animals' nutrition and external features. In the evaluation phase, pupils made broader generalizations about animals' behavioural and structural adaptations to winter. They compared, contrasted and evaluated the environmental effects on the ways in which animals have adapted to winter and highlighted the biotic elements in the winter ecosystem. In the planning phase, pupils had multiple goals in their value claims and they reported a sense of independence and dedication during the learning process. Results indicate that Vee heuristics could be considered to be a tool for improving the learning process in pupils. In biology it encouraged learning for understanding, engagement, enjoyment, independence and self-efficacy.
\end{abstract}

Key words: biology education, environmental education, secondary school, Vee heuristics, winter ecology.

\section{Introduction}

Research on winter-related ecology and the study of interrelations between organisms and the cold environment has long traditions in Finland. How can we, at the secondary school level teach such complex and abstract phenomena as the seasonal period of decreased solar, thermal and nutritional energy? This paper focuses on pupils' learning process concerning animals' winter ecology and presents the Finnish viewpoint on the use of Vee heuristics in biology education.

Many previous studies have shown that primary or secondary school pupils do not understand essential ecological concepts, for example adaptation, food chain, ecological niche, cycle of matter as well as the structure of ecosystems or the nature of the interrelations within the ecosystems (see e.g. Grotzer \& Bell Basca, 2003; Lin \& Hu, 2003; Magntorn \& Helldén, 2007a; Sander, Jelemenska \& Kattmann, 2006; Yip, 2009). Grotzer and Bell Basca (2003) argued that the difficulty in understanding ecosystem concepts stems partly from the inability to grasp the underlying causality that structures the concepts. Also Ashelford (2002) highlighted that concept adaptation for example, has many meanings in biology teaching and learning and is an area where conceptual difficulties frequently arise. The main causes for conceptual 
PROBLEMS

OF EDUCATION

IN THE $21^{\text {st }}$ CENTURY

Volume 47, 2012

difficulties are failure to distinguish both between adaptations as a process of short-term change and a long-term evolutionary change as well as the failure to distinguish adaptation as being a process of change from its meaning as a description of current features that aid survival (Ashelford, 2002).

Several developments in biology education aim to improve pupils' ability to think scientifically. According to Gehring and Eastman (2008) a major challenge in the teaching and learning of biology is the development of students' abilities to gather, analyze, apply and synthesize information. These skills are also important for students to underlying evidence that supports basic biological concepts. Asking questions for example is an essential component of the practice of science (Yip, 2004). According to the study of Yip (2009), asking questions helps pupils make a distinction between causal and teleological explanations. Teleological explanations are questions required for the significant importance or advantage of certain biological processes. Functional or physiological explanations primarily answer the "how" questions and demand the underlying mechanisms of how processes work; evolutionary explanations answer the "why" questions (Yip, 2009).

This being so, an inquiry-based, field work approach is important and essential in teaching and learning about ecology at the primary and secondary school level (e.g. Finn, Maxwell, Calver, 2002; Hamilton-Ekeke, 2007; Lindeman-Matthies, 2006; Sander et al., 2006). Magntorn and Helldén (2007a) had a study of ecology teaching and learning in a Swedish primary school class which they used perspective from organism autecology to synecology and finally to the whole community or systems level. In ecology education, an inquiry-based study of a single organism has been shown to be highly motivating for students. Naming an organism also provides opportunities for discussion and inquiry and allows children to make sense of the world around them (Patrick \& Tunnicliffe, 2011). According to the study of Magntor and Helldén (2007b), naming animals has little intrinsic value but when naming has the same ecological function, then taxonomy is important for reading about nature. Students have to be introduced to observing the structures - both biotic and abiotic - and to be familiar with ecological models that can be related to these structures (Magntorn \& Helldén, 2007b).

\section{Problem of Research}

In biology education field work is not always possible, therefore other learning environments are important. Previous studies (e.g. Wilde \& Urhahne, 2008; Krombass \& Harms, 2008) show that natural history museums are well-respected educational resources with authentic objects and realistic surroundings. A detailed study of any organism's characteristics may be carried out more easily in a museum environment than in the natural world. According to the study of Tunnicliffe and Laterveer-de Beer (2002) a museum exhibition promotes the understanding of morphology and forms of locomotion. It is important however to remember the results of Tunnicliffe's (1996) previous study revealing that when children look at animals in exhibits, they mention anatomical features such as size, shape and colour but they do not mention conservation issues or habitat. Thus, animals in museums do not provide a realistic view of the natural world, for example malnutrion or disease. Falk and Storksdieck (2005) have also shown in their studies that students are not just familiarised with facts and concepts of animal species; in the museum context they may also gain a better awareness of animals' physical size or the texture of their fur. Young children rely on anatomical structures of group animals while older children use taxonomy, habitat and behaviour in addition to anatomical structures (Tunnicliffe \& Reiss, 1999).

In the museum, learning takes place at many levels; in addition to the cognitive level, motivational and affective components are also integrated if the tasks are quite open (Wilde $\&$ Urhahne, 2008; Krombass \& Harms, 2008). Research on pupils' interest, goals and motivation 
in science and especially in biology education (e.g. Prokop, Prokop, Tunnicliffe \& Diran, 2007;

PROBLEMS

OF EDUCATION

IN THE $21^{\text {st }}$ CENTURY

Volume 47, 2012

Uitto, Juuti, Lavonen \& Meisalo, 2006) helps the teacher to devise strategies to enhance students' interest and develop a positive attitude towards science and biology education. According to the study of Lindemann-Matthies (2006) this is possible if children's awareness of nature in their daily lives is promoted as well as an interest in and knowledge of local plants and animals. Without knowledge and a relationship with organisms in their local environment, people might not notice what happens to them (Lindemann-Matthies, 2006). In previous studies, Pintrich, Marx, and Boyle (1993) for example, have shown that motivational beliefs including goals, values and self-efficacy also play a major role in conceptual change.

\section{Research Focus}

In this study, eighth graders used Åhlbergs' modified Vee heuristics which consists of ten questions related to three different phases: the planning, implementation and evaluation of the learning process. The ideas presented in the value basis and theoretical basis sections of the planning phase (questions 2-5) provide an insight into how pupils' ideas develop. The implementation phase includes one question (question 6). The ideas presented in the sections, knowledge and value claims in the evaluation phase (questions 7-10), indicate how valuable this process of working through the heuristic has been to the pupils (Figure 1).

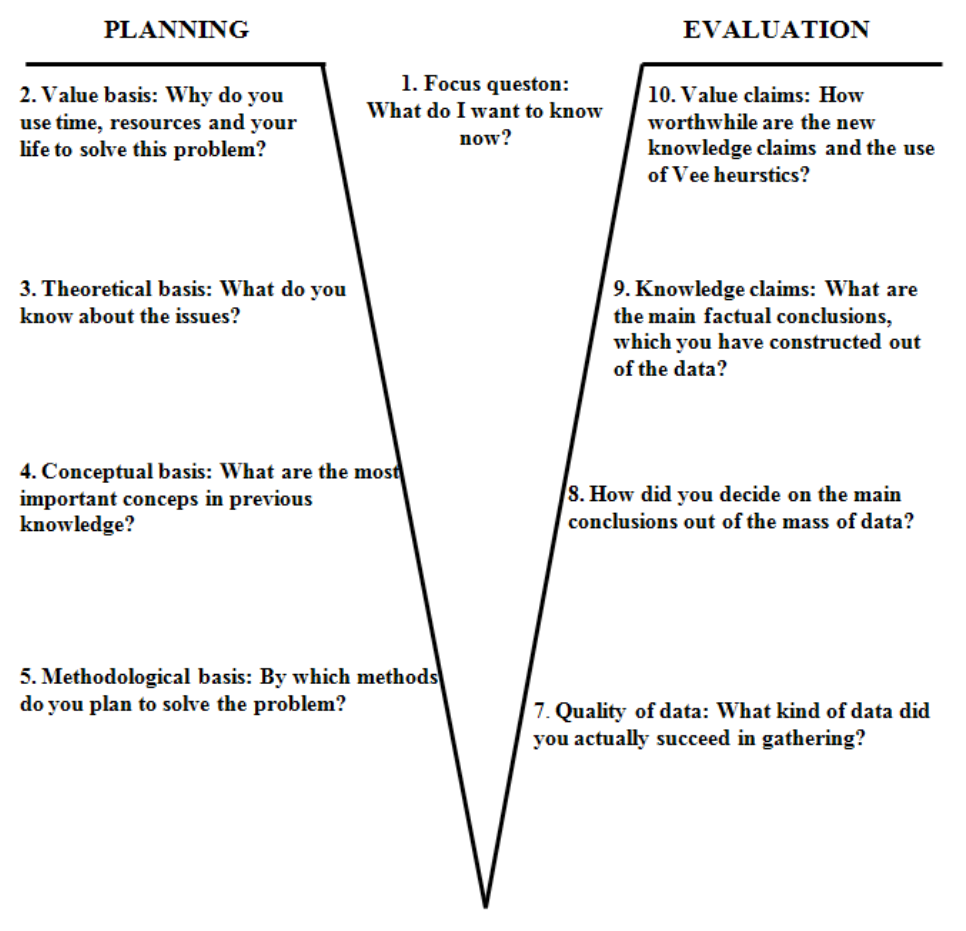

IMPLEMENTATION

6. What do you have to do in order to construct answers to

the focus questions?

Figure 1: A model of Vee heuristic and its ten questions (see Åhlberg, 1998) which pupils used during their biology learning process. 
PROBLEMS

OF EDUCATION

IN THE $21^{\text {st }}$ CENTURY

Volume 47, 2012

Vee heuristics can be used to implement inquiry-oriented science activity (Tsai, Liu, Lin \& Yuan, 2001) and it is a relatively unknown method at the secondary school level (see Novak, Gowin \& Johansen, 1983; Ugwu \& Soyibo, 2004). According to Novak (2002), the comprehension of Vee may explain in part, why Vee heuristics are currently less popular than, for example concept maps. Novak et al. (1983) also wrote that a couple of years of work with Vee would be needed for students to acquire effective use of Vee heuristics. Vee heuristic in its basic form was firstly introduced by Gowin (Novak et al., 1983; Novak \& Gowin, 1984, Mintzes, Wandersee \& Novak, 2001). In Finland, Åhlberg (1998) devised the modified Vee heuristic (see Figure 1.) because there were some problems with the original Vee heuristic (see also Vanhear \& Pace, 2008). For example, when students were asked to state their "world view" many of them were unfamiliar with the term. Modified Vee heuristics contain value claims instead of "word view". (Åhlberg, Äänismaa \& Dillon, 2005.) Thus, Åhlberg and his colleagues have for over 20 years, developed and tested Vee heuristics with students in a variety of disciplines at the university and school level (e.g. Åhlberg \& Ahoranta, 2002; Åhlberg et al., 2005). The main difference with Gowin's original Vee heuristic and Åhlberg's modified version, is that Åhlbergs' Vee heuristic contains ten theoretically justified steps to high-quality learning and thinking (see Novak et al., 1983; Åhlberg et al., 2005).

Previous studies have shown that Vee heuristics has much potential in promoting authentic inquiry (Åhlberg et al., 2005; Vanhear \& Pace, 2008). Although it has been used at the university and primary school level, this approach is relatively new in secondary schools and not much research has been documented. Thus, it is of interest to study how Vee heuristics can be implemented in a biology learning process at the secondary school level and to find out how pupils respond when they are asked to formulate their focus questions and design investigations in order to answer them. The main research question is: how do pupils use Vee heuristics in the biology learning process concerning winter ecology?

The specific research questions are:

1. What do the pupils want to know about the subject "animals in winter"?

2. What kind of value basis do pupils have in the beginning of the biology learning process?

3. What are the pupils' conceptual and procedural knowledge in the planning, implementation and evaluation phase?

4. How worthwhile is the new knowledge and the use of the Vee heuristics?

\section{Methodology of Research}

The participants of this study were pupils $(\mathrm{N}=92)$ from six classes in a rural secondary school in Central Finland. The pupils were aged from 13-14 and the sample consisted of 48 boys and 44 girls who were taught by the same biology teacher. The biology teaching unit "How do animals spend the winter", which was under study here, belongs to the normal timetable of the school and followed pupils' normal daily routines. The pupil-directed inquiry-based biology learning unit was rooted in constructivist pedagogy. It has been designed to create a learning environment where pupils use Vee heuristics to build upon their knowledge in an effort to experience enriched understanding. Interaction of new knowledge and prior knowledge is accomplished through Vee heuristics with its ten questions (see Figure 1).

The possibilities for studying winter ecology outdoors were limited because the biology learning unit took place at a time when there wasn't any snow. Thus, the project was mainly based on materials from texts and some of the biology lessons were held in the local Science museum which is located near the school building. There, pupils could relatively independently explore exhibits of a terrestrial forest, freshwater ecosystem and farmyard as well as skulls and 
skeletons of vertebrates and invertebrates. Animals were those living freely in the wild, because it was recommended that domesticated animals should not be used as study species during this biology learning unit.

This biology learning unit, which is also based on the Finnish Biology education curricula (grade 8) on ecological issues, is mainly integrated into the core content "Nature and Ecosystems". The goal of the national core curriculum is for biology instruction to be founded on inquiry-based learning, developing the pupils' thinking in Natural Sciences as well as giving pupils the ability to observe and investigate nature, life and its phenomena. In the 8th grade, pupils learn about ecology, biodiversity and nature conservation. The curriculum covers topics such as interactions between organisms, energy cycles, biodiversity as well as protected areas and endangered species. Biology education should have, as one of its aims, the development of biological literacy so that all pupils can make decisions about biological issues and improve their ability to think scientifically: ideas related to the design of investigations and the collection, presentation, analysis, and evaluation of the resulting evidence. Ecological issues are also integrated in the grade 9 core content "Life and Evolution". (National Board of Education, 2004.)

This paper focused on an examination of pupils' Vee heuristics in the context of ten biology lessons. Research data was also collected through concept maps, diaries, self evaluation reports, essays, and pupils' marks. Vee heuristics reveal pupils' perceptions through their individual ways of describing issues. From the Vee heuristics the data gathered was personally produced by the pupils using concepts familiar to them in their own style of writing. According to the study of McLaren and Webber (2009) writing tasks play an important role in facilitating pupils' thinking and domain centered learning in the sciences. Writing activities can be useful a aid in conceptual comprehension and retention as well as in promoting reflection. Mintzes, Wandersee, and Novak (2001) also highlighted that writing should be an integral part of every school science experience. They think that written assignments are less frequently used by many teachers because reading and evaluating them is often viewed as time consuming.

\section{Biology Learning Unit}

All the six groups had 10 lessons, each lasting 45 minutes. The aim of the biology learning unit was to develop pupils' skills of how to learn, such as planning, monitoring and evaluation. The main idea of the biology lessons was to understand how animals spend the winter, reporting the interactions of animals and their environments and describing what shapes the patterns of distribution and abundance of different species had. Each lesson started and ended with a classroom discussion framing the task to be studied. All of the pupils had used Vee heuristics and concept maps at least once before this study but they did not have any long term experience with Vee heuristics. Pupils were encouraged to consult scientific literature. The first major decision that each pupil had to make concerned the focus question or questions selected for the study. During this time a number of opportunities for informal feedback, advice and discussion were provided. Pupils were allowed to independently seek assistance and communicate their findings with other pupils and the teacher. Formal summative assessment consisted of a written report.

In phase 1, the pupils discussed their own views about animals in winter and shared them with the class, giving pupils an idea of some of the issues related to the subject. They preferred single project work rather than group or pair work, although in many cases the pupils worked together in the lessons. At the beginning of the unit, each pupil individually constructed a concept map based on issues that they knew about the subject "animals in winter". Pupils also wrote up every lesson in a diary which was used to reflect upon their thinking. In phase 2 , the teacher and pupils visited the local Science museum. Firstly, pupils identified the focus 
PROBLEMS

OF EDUCATION

IN THE $21^{\text {st }}$ CENTURY

Volume 47,2012

questions in the Vee heuristics which promote inquiry that eventually leads to new biological knowledge. Secondly, pupils worked with issues on the left side of the Vee heuristic, the value, theoretical, conceptual and methodological bases (questions 1-5). In phase 3, pupils gathered data to answer their questions (implementation phase in Vee heuristics). They also conducted library research, surfed on the Internet and visited the local Science museum again. At each visit a member of the museum staff was present and helped the pupils who were also asked to write a report as a part of their homework. In phase 4, they completed issues the right side of the Vee heuristics; quality of data, value and knowledge claims (questions 7-10). At the end of the project, pupils constructed a concept map based on issues known about the subject. Vee heuristics and concepts maps were discussed with other members of the class. The sharing of experience at the end of lessons provides a good chance for the teacher to consolidate their understanding of learning skills. In phase 5, pupils shared their experiences. Each pupil gave a 5-10 minute oral-presentation and also completed a self-evaluation task in their diary. At the end of the unit, pupils made a summary in their diaries about the subject "animals in winter" and wrote short self evaluation reports. Pupils' written reports comprised of about 10-12 pages.

\section{Data Analysis}

The Vee heuristics $(\mathrm{N}=92)$ were qualitatively analysed by using the methods of inductive content analysis. First, the Vee heuristics were carefully read through in order to understand their content, then each of the pupils' Vee heuristics with their ten questions were analysed. Codes and categories specifically emerged from the pupils' writings. From the first reading, core concepts (codes) were identified; these initial codes were then revised after a second and third reading. Codes with common themes were subsequently placed into categories that reflected the pupils' conceptions. The Vee heuristic with its ten questions were also analyzed by counting core concepts, although changes in the average number of concepts in the planning, implementation and evaluation phase alone, do not provide conclusive evidence of conceptual change.

Some ideas from previous studies have also been utilised. For example, the SOLO taxonomy is used to describe the complexity of knowledge claims in the evaluation phase. According to Biggs and Collis (1982), the Structure of the Observed Learning Outcome (SOLO) taxonomy is divided into five major levels: 1) pre-structural, 2) uni-structural, 3) multi-structural, 4) relational and 5) extended abstract. In this study, is used only four major levels to describe the complexity of the knowledge claims, the pre-structural and uni-structural levels being combined. Pre-structural and unistructural knowledge claims included unconnected information as well as simple and obvious connections with concepts. Multistructural knowledge claims included concepts which a number of connections may be made, but the meta-connections between them are missing. The relational level included knowledge claims made up of concepts which are linked each other and the parts are in relation to the whole. Extended abstract level knowledge claims had connections with concepts which contained generalised principles and ideas.

Analysis of the Vee heuristics was done by triangulation of the data. Triangulation reduced subjectivity, increasing the validity of data analysis and interpretation of the results (e.g. Patton, 2001). Most of the codes and themes were assigned to the same category by the two researchers who independently grouped the codes into individual categories. Any discrepancy which occurred was settled through discussions and negotiation between the researchers. The author, being a teacher, attempted to foresee limitations by emphasising that they should answer truthfully and accurately. The descriptive themes were therefore constructed, based on the core ideas that emerged from the different pupils. Vee heuristic were used with six different groups from which, although rather small in size, some conclusions could be made. These limitations were taken into account in the interpretation of the results. 


\section{Results of Research}

The results are presented through examples from pupils' Vee heuristics with its ten questions. The planning phase in this study included the left side of Vee heuristics; focus questions, value basis, theoretical, conceptual and methodological base (questions 1-5). The implementation phase includes one question in Vee heuristics; what do you have to do in order to construct answers to the focus question (question 6). The evaluation phase is the right side of the Vee heuristics and included analysis of the data, main conclusions as well as new knowledge and value claims (questions 7-10).

\section{Focus Questions in the Planning Phase}

What do the pupils want to know about the subject "animals in winter"? The number of focus questions presented by the pupils is shown in Table 1. Most of the pupils asked 3-4 questions about animals in winter and altogether 309 questions asked on this subject (see Table $1)$.

Table 1. The number of focus questions in Vee heuristics from the planning phase.

\begin{tabular}{|c|c|c|c|}
\hline $\begin{array}{c}\text { Number of focus questions } \\
\text { in pupils Vee heuristics }\end{array}$ & Girl & Boy & Total \\
\hline 1 & 0 & 2 & 2 \\
\hline 2 & 10 & 12 & 22 \\
\hline 3 & 51 & 51 & 102 \\
\hline 4 & 84 & 84 & 168 \\
\hline 5 & 5 & 10 & 15 \\
\hline Total & 150 & 159 & 309 \\
\hline
\end{tabular}

Focus questions were also classified into five categories according to the question type: factual, explanatory, comparative, descriptive and conditional questions. Most of the pupils' focus questions were "which" questions (48 \%), and the pupils were able to answer these questions by using factual knowledge. Factual questions also included measuring and counting questions which concerned e.g. species list, place, count or time. Pupils asked questions such as "Which animals are in torpor?", "Which rodents change their coat colour?", "Where does the bear sleep in winter?", "Where does the lynx pass the winter?" and "How many tits survive and pass the winter?"

"Why" or "how" questions (32\%) showed a typical way of thinking in biology. These focus questions required a relatively simple explanation or a greater degree of insight as well as an understanding the primary causes and evolutionary and teleological explanations. Some of these questions have no simple answer maybe no answers. "How" questions required functional and physiological explanations and "why" questions evolutionary explanations. Pupils investigated how animals adapt to physical environments, how populations grow and what shapes the patterns of distribution and abundance of animals. Pupils asked questions such as: "How was the lynx adapted to winter?", "How have some small rodents adapted to winter?", "Why are owls active in winter?" and "Why are some mammals white in winter?", "How do animals pass the winter?", "Why are some rodents in deep hibernation?"

Focus questions which included an animals' external features, for example; the colour of an animal's fur and the structure of an animal's skull, are descriptive questions (14\%) as well 
PROBLEMS

OF EDUCATION

IN THE $21^{\text {st }}$ CENTURY

Volume 47, 2012

as animals' hibernation types, nutrition habits and species lists. Pupils asked questions such as: "What kind of habits do rodents have in the winter?", "What kind of fur do animals have in the winter?", "What kind of structural features exist among small rodents?" and "What kind of nutrition does a bear have?"

Only a few focus questions were comparative questions (4\%) which help pupils analyze and classify for example, animals' behaviour and structural features, animals' hunting habits and the structure of animals' skulls. These questions were also linked to those relating to species identification. Eight graders asked questions such as: "What are the main differences between owls and tits in hold they pass the winter?", "What are the structural differences between rodents?" and "What are the advantages and disadvantages of hibernation?"

A few of the focus questions are conditional questions $(2 \%)$ which encourage pupils to explore the properties of animals and make predictions about phenomena or changes in the future. These questions also required evolutionary explanations as well as a physiological process of explanations. For example pupils asked: "What will happen if small rodents do not change their fur colour?" and "What would be the advantage of such behaviour to mammals?"

In conclusion, pupils raised questions about how owls generally survive the winter and what is their winter nutrition. Animals' external features such as skulls were important in pupils' focus questions and they used the main concepts of carnivores and rodents which are concepts from order. In focus questions, pupils used the concept of species for example bear and lynx, both of which are carnivores and endangered species in Finland. As well as the owls, pupils were generally interested in animals' overwintering. It is important to note that pupils wanted to raise several focus questions instead of just one and the quality of them was quite factual. There were also a few pupils who were not able to produce any focus question at all.

\section{Value Basis in the Planning Phase}

Pupils' descriptions with the number of value claims $(n=235)$ are classified into eight categories shown in table 2 . In this paper, we define value claims as a construction that includes different motivational elements and thus pupils' value claims were classified into two themes according to the motivational level: intrinsic value claims, external value claims. Generally each pupil had more than one value claim in which they wrote about their interests, goals and motivation.

Table 2. The number of value claims $(n=235)$ in pupils' Vee heuristics.

\begin{tabular}{|c|c|c|c|c|}
\hline Value claims & Girls & Boy & Total & $\%$ \\
\hline Intrinsic value claim & & & & 66 \\
\hline Learning & 48 & 37 & 85 & 36 \\
\hline Interesting & 24 & 11 & 35 & 15 \\
\hline Independent working & 10 & 5 & 15 & 6 \\
\hline Benefit in the future & 9 & 13 & 22 & 9 \\
\hline External value claims & & & & 33 \\
\hline Better grade & 18 & 14 & 32 & 14 \\
\hline Included schoolwork & 12 & 12 & 24 & 10 \\
\hline I don't want to do it & 2 & 9 & 11 & 5 \\
\hline other students do I too & 1 & 8 & 9 & 4 \\
\hline Other & & & & 1 \\
\hline I don't know & 1 & 1 & 2 & 1 \\
\hline Total & 125 & 110 & 235 & 100 \\
\hline
\end{tabular}


More than half of the pupils had intrinsic value claims and one third of the pupils'

PROBLEMS

OF EDUCATION

IN THE $21^{\text {st }}$ CENTURY

Volume 47, 2012

descriptions expressed that they wanted to learn. Pupils were also interested in the winter ecology of animals; they were interested in the content of the biology lesson and learning in general. The Biology learning unit was enjoyable and satisfying in itself in addition to learning having positive advantages they felt they would benefit from the use of knowledge in the future. Pupils also reported a strong sense of intrinsic motivation, independence, dedication and development of critical reasoning. Pupils reported: "It is interesting to read", "I want to learn more" and "It is important for me to know more about hibernation."

Pupils had external value claims and performance goals in their value claims, such as increasing the number of credits and getting better examination marks. The reward is dependent upon the success or failure of the task and there is also peer pressure in the classroom. Pupils also wrote that the teacher directed the teaching and learning process and that they expected to be told what to do and hold to do it. External value claim goals included descriptions in which pupils wrote that they didn't like this biology learning unit and were dissatisfied with it. They were not interested in the task and did not see the importance and value of the biology learning unit. Levels of self efficacy varied among the pupils who wrote that: "The teacher asked me to do this learning project", "Because I do this work I can get a better number of credits in biology", "I must to do this because it is our school work.", "Other pupils do this task too", "I take no interest in overwintering", "I would prefer to do something else" and "Biology and this project is boring" A few pupils did not know why they had to use their time and resources to solve the problem. They wrote briefly "I don't know."

\section{Conceptual Knowledge in the Planning, Implementation and Evaluation Phase}

Pupils wrote the theoretical basis according to the question: What do you know about the issues? Pupils have many "everyday perspectives" and misconceptions on how animals pass the winter. They used concepts which are not scientifically exact, for example they used the concept of food instead of nutrition. Some pupils' also had misconceptions concerning animals' hibernation. Some of them wrote that "the hedgehog is in deep torpor instead of hibernation." Pupils also had anthropomorphic explanations, for example they wrote that a "rodent eats cheese", "a wolf fear is afraid of fire" and "an owls' home is up a tree". Factual knowledge claims are typical but teleological reasoning was quite rare in the planning phase. Some of the pupils wrote that "Many birds migrate south in winter in response to cold weather or the shortening length of the day."

Pupils' conceptual knowledge and the most frequently mentioned descriptions in the planning, implementation and evaluation phase is shown in table 3. 
PROBLEMS

OF EDUCATION

IN THE $21^{\text {st }}$ CENTURY

Volume 47, 2012

Table 3. The number descriptions in the planning, implementation and evaluation phase.

\begin{tabular}{|c|c|c|c|c|}
\hline Description & Planning phase & $\begin{array}{c}\text { Implementation } \\
\text { phase }\end{array}$ & Evaluation phase & Total \\
\hline Hibernation & 28 & 10 & 3 & 41 \\
\hline Nutrition & 22 & 4 & 3 & 29 \\
\hline Owl & 18 & 23 & 58 & 99 \\
\hline Skull & 16 & 4 & 37 & 53 \\
\hline Rodent & 16 & 5 & 14 & 35 \\
\hline Overwintering & 16 & 10 & 0 & 26 \\
\hline Endangered sp. & 16 & 04 & 15 & 35 \\
\hline Habitat & 14 & 2 & 2 & 18 \\
\hline Carnivore & 12 & 0 & 0 & 12 \\
\hline Mixed flock & 12 & 0 & 0 & 12 \\
\hline Bird of pray & 12 & 0 & 0 & 12 \\
\hline Rovtand & 10 & 0 & 0 & 10 \\
\hline Deep hibernation & 10 & 0 & 0 & 10 \\
\hline Lynx & 0 & 20 & 25 & 45 \\
\hline Aegolius f. & 0 & 18 & 25 & 43 \\
\hline Bear & 0 & 17 & 17 & 34 \\
\hline Wolf & 0 & 14 & 20 & 34 \\
\hline Parus major & 0 & 11 & 0 & 11 \\
\hline Bubo bubo & 0 & 11 & 15 & 26 \\
\hline Clethrionomys g & 0 & 11 & 0 & 11 \\
\hline Strix aluco & 0 & 11 & 11 & 22 \\
\hline Big predator & 11 & 0 & 15 & 26 \\
\hline Adaptation & 0 & 0 & 45 & 45 \\
\hline Small rodents & 0 & 0 & 38 & 38 \\
\hline Mammals & 0 & 0 & 22 & 22 \\
\hline Tits & 0 & 0 & 21 & 21 \\
\hline Mouse & 0 & 0 & 15 & 15 \\
\hline Asio otus & 0 & 0 & 18 & 18 \\
\hline Spoor & 0 & 0 & 17 & 17 \\
\hline Vole & 0 & 0 & 16 & 16 \\
\hline Total & 213 & 171 & 452 & 836 \\
\hline
\end{tabular}

What are the most important concepts already familiar from previous knowledge? Altogether the pupils had 213 concepts in the planning phase. Pupils wrote about animals' behavioural or physiological adaptation to winter and the environment. Pupils used concepts of torpor as well as hibernation. They wrote that hibernation allows some animals to stay sheltered and survive periods of winter cold. They described the quality of hibernation, for example the level of being awake during the winter and they wrote lists of animals which are in hibernation as well as those in deep hibernation. Pupils wrote: "Hibernation is found in animals with inadequate external food reserves", "Bear goes into hibernation and arouses from hibernation", "Animals store and use food prior to hibernation" and "Some mammals are in deep torpor/deep hibernation."

Pupils used the concept of nutrition, or they just wrote how and what animals eat as well as how they change their nutritional habits or habitat during the winter time because of the food shortage hibernation helps animals to avoid difficulties in finding sufficient nutrition over the winter. Pupils used the concepts of carnivore and rodents and wrote: "The nutrition of most herbivorous animals is different in the winter", "Mammals choose their food plants carefully", "Many mammals eat food stocks they have gathered" and "When the snow cover is thick owls have difficulty in finding and gathering food". 
Owls are one of the core concepts in pupils' Vee heuristics. Migration is one avoidance

PROBLEMS

OF EDUCATION

IN THE $21^{\text {st }}$ CENTURY

Volume 47, 2012

strategy in birds but most of the owls did not migrate during the winter. Predator and prey relationship is important because owls suffer if its food is a species that cannot tolerate a cold environment. Pupils wrote about the owls' habitats, behaviour and nutrition during the winter: "Owls have extensive habitats in winter", "Owls are active in winter", "Winter is the critical season for owls because of the scarcity of food resources" and "Rodents are the owls prey."

In the planning phase, the pupils' main concepts are concepts from order such as carnivore and rodent. They also use the core concept "endangered species" and described the exterior features or external structures of animals, for example skull, rovfood and canine teeth). They wrote: "Carnivores' skulls are big and sharp-toothed", "Carnivores such as the bear have large habitats", "Owls eat rodents in winter time" and "Wolf is a predator and belongs to an endangered animal species" Many of the animals stay active in winter and there the pupils used the concept "overwintering". Meaning specializing particular habitat change, for example migration or behavioural change in predation: "Tits live in mixed flocks in winter", "Mammals had many overwintering habits", "During the long winter the bear wakes up but does not eat" and "Some animals spend long periods of time in burrows in the winter".

The number of core concepts and descriptions in the implementation phase in Vee heuristics is shown in table 3. To the question What do you have to do in order to construct answers to the focus questions? pupils answered quite shortly, mainly they listed concepts. In the implementation phase owls are the main concept and pupils mentioned many species of owls, for example Tengmalm's owl (Aegolius funerus), the Eurasian eagle-owl (Bubo bubo) and the Tawny owl (Stricx aluc). Pupils wrote: "I investigate Tawny owls' distribution and breeding", "The most important thing is the owls' food supply in winter time", "Owls' hibernation in Finland" and "Some owls are endangered in Finland".

In addition to the owl species, pupils used the concept of lynx, bear and wolf. The concepts of hibernation and overwintering were also frequently used. For example: "One example of a hibernator in Finland is the bear and I wrote about it" and "I focus my studies on animals without external reserves of the nutrition because they must use internal reserves and others hibernate". Secondary school pupils also used the concept of Parus major and mole .They wrote: "I investigate the bank mole (Clethrionomys glareolus) and how it passes the winter", "Tits for example, Parus majors' overwintering in Finland" and "How tits pass the cold winter?"

What kind of data did you actually succeed in gathering? The number of core concepts and descriptions in the evaluation phase in Vee heuristics is shown in table 3. They wrote about animals' morphology, behaviour, life cycles and autecology and used concepts of rodent, predators as well as endangered animals. In the evaluation phase, pupils mainly highlighted synecology, for example the ecological relationship of a community. The systemic view which means relations between biotic and abiotic components and the flow of energy and cycling of matter in the ecosystem, was seldom mentioned. The main concept of mammals includes many subconcepts such as bear, vole, mouse, wolf and lynx.

Owls were the main concept in the evaluation phase but pupils also used sub concepts such as the species Bubo bubo, Asio otus, Strix aluco, Tawny owls, Tengmalm's owl and Aegolius funerus, all of which are typical owls in winter in Central Finland. Owls are presented as one of the top predators in food chains and food webs. Owls have a wide variety of species as their prey though they have preferences in ranking order of choice when there are alternatives available. Animals respond to each changing condition in their environment, the effects of which may largely be determined largely by the responses of other community members. Temperature does not affect only one of the species: it also affects the owls' competitors as well as its prey. Pupils wrote: "Owls occur in various habitats for which they have adapted their foraging behaviour", "Owls prey on animals such as tits and rodents. Fluctuations in food supply are typically in the 
PROBLEMS

OF EDUCATION

IN THE $21^{\text {st }}$ CENTURY

Volume 47,2012

80 life of owls", "Owls are active winter birds which do not migrate", "Food shortage in winter has limited the distribution and abundance of owls" and "Some owls are endangered".

In the evaluation phase, pupils used the concept "adaptation" and they wrote about animals' structural and functional adaptation to it. Structural or functional adaptation included examples of shivering and regulation of temperature. Some of the responses to changing conditions include acquiring a different coat in the autumn, a thick one underlain by a thick layer of fat. Mammals as well as birds (=endotherms) expend more and more energy maintaining the constant body temperature and to achieve this alm they have a high requirement for food. Pupils wrote: "Bear: one of its external features is thick fur which is grown twice a year", "Colour change to reduce risk of predation", "Tits huddle close together", "Once feeding tits has started it has to continue regularly", "Some birds such as tits also take advantage of each other's body heat as a means of coping with the cold weather (huddling)" and "Mammals and tits that live in cold temperatures are insulated from the cold with extremely dense fur or feathers and extra layers of fat".

Environmental conditions act primarily to modulate the rates of physiological processes and many conditions are important stimuli for growth and development, preparing an animal for conditions that are to come. For example, although pupils did not write about the external signal such as is the length of the day in the approaching of winter, they wrote: "The wolf is able to add to heat production by shivering", "Mammals and birds retain a relatively constant body temperature", "Hibernation in a mammal is a state of reduced core temperature", "The bear's active body temperature is near to $37^{\circ} \mathrm{C}$ " and "Reduction in heart rate and body temperature is important to mammals".

In their writings, pupils used concepts of small rodents and large predators. In winter ecology the relation between the body's surface and mass plays an important part in the effectiveness of insulation, the percentage change in winter insulation being greater in small animals than in large ones. In cold climates, animals have a low surface area in ratio to volume (short ears and limbs) and this reduces heat loss through the surface. Pupils wrote in their Vee heuristics: "The lynx is an example of the ratio between long-leg surface and body-weight", " The vole has a body temperature that does not vary with the external environment", "Some big predators solve the problem by cooling their extremities" and "Maintaining cold extremities is adaptation in response to a cold environment".

Identifying animals is possible by the aid of the shape and size of a skull. Teeth are another indicator of species. Identification of the teeth can be the first step towards discovering what type of animal the skull belonged to and what the animal ate. Additional information about the animal also can be gleaned from skulls, for example the age and general picture of the health of the animal: "With the aid of skulls I can see evidence of similarities and differences in animals" and "Skull observation gives information about what the animals ate". Many animals stay active in winter and pupils can observe and study animals' tracks and footprints in the snow. Pupils wrote: "Identification of animals' spoor and feeding habits", "Identification of footprints and droppings in winter", "The width of the forepaw is important" and "The bark mole stores food in the burrow and lives in forest. It is easy to see the burrows in snow".

Ecology included abundance of various types of population dynamics and cycles. Only a few pupils used concept cycles although small herbivorous mammals such as voles and lemmings tend to have 3-to 4-year cycles. These cycles may be caused by food shortage during winter and cycles may be due to predator-prey interactions: "Predator - prey relationship is important among animals", "The number of rodents is important", "The lynx competes for food and living space", "The home range of the tit usually changes with the season" and "Breeding conditions and the number of breeding pairs".

In the evaluation phase, secondary school students were interested in endangered species which is a population of organisms at risk of becoming extinct due to begin few in numbers or 
threatened by the parameter of a changing environment or predation. In Finland, one example of an endangered species is the wolf and the otter, lynx and bear are also threatened to some

PROBLEMS

OF EDUCATION

IN THE $21^{\text {st }}$ CENTURY

Volume 47,2012 extent. Owls too are presented to pupils as an example of an endangered species; "Some owls are endangered" and "The lynx and bear are also endangered species".

When comparing the planning and implementation phases with the evaluation phase, concepts used by the pupils in the evaluation phase increased in number, were diversified and more abstract: adaptation to winter, mammal, rodent and concepts which included taxonomy classification of genius, family, order and class as well as species. For example, owls occur in various habitats for which they have adapted their foraging behaviour once a broad spectrum of prey such as rodents (vole) and tits. In the evaluation phase pupils used generalised concepts concerning bird species identification. However, there were only a few descriptions about abiotic factors such as light and temperature.

\section{Procedural Understanding in the Planning, Implementation and Evaluation Phase}

In the planning phase, the methodological basis included Vee heuristic questions: Which methods do you plan to use to solve the problem? Pupils made observations in the museum and consulted scientific literature. Pupils well encouraged to decide the size of their project and the timing of their work themselves. Table 4 seems to suggest that pupils used processing skills in the planning phase i.e. the use of data sources and illustrations. Pupils wrote: "I read newspapers and wrote in my diary", "I asked the biology teacher", "I searched for knowledge from the internet" and "I went to the library and science museum to look at animal skulls".

In the implementation phase, pupils mentioned in the methodological basis that they searched for information, compared, read and made some research, while in the evaluation phase pupils used editing, selection, mapping, drawing and summarizing. Pupils wrote: "I used collection, analysis and interpretation of the data", "I had active learning using text", "I made decisions about biological issues", "I compared the findings with data from other sources", "I used identification books" and "I presented the owls' distribution area with aid of a map".

In the evaluation phase, some pupils were more interested in finding generalizations from a single observation of the biotic and abiotic components and how they interacted. They used taxonomic specimens and identification books with the aid of drawings and maps pupils showed the density of populations in Finland. Using diagrams they showed cycles of abundance with peaks around every year and also demonstrated that show that when the temperature is a few degrees above zero, organisms may be forced into extended periods of inactivity. 
PROBLEMS

OF EDUCATION

IN THE $21^{\text {st }}$ CENTURY

Volume 47, 2012

Table 4. The classification and number of methods which pupils in the planning and evaluation phase.

\begin{tabular}{|c|c|c|c|c|c|c|c|}
\hline Method & $\begin{array}{c}\text { Planning } \\
\text { phase }\end{array}$ & $\begin{array}{c}\text { Planning } \\
\text { phase }\end{array}$ & $\begin{array}{c}\text { Planning } \\
\text { phase }\end{array}$ & $\begin{array}{c}\text { Evaluation } \\
\text { phase }\end{array}$ & $\begin{array}{c}\text { Evaluation } \\
\text { phase }\end{array}$ & $\begin{array}{c}\text { Evaluation } \\
\text { phase }\end{array}$ & Total \\
\hline & Girl & Boy & Total & Girl & Boy & Total & \\
\hline Drawings/maps & 30 & 35 & 65 & 60 & 48 & 108 & 173 \\
\hline Books & 28 & 20 & 48 & & & & 48 \\
\hline Reading & 24 & 22 & 46 & 28 & 28 & 56 & 102 \\
\hline Science museum & 19 & 10 & 29 & & & & 29 \\
\hline Textbooks & 13 & 13 & 26 & & & & 26 \\
\hline Computer & 11 & 9 & 20 & & & & 20 \\
\hline Writing & 6 & 9 & 15 & 8 & 15 & 23 & 38 \\
\hline Newspapers & 4 & 6 & 10 & & & & 10 \\
\hline Diagrams & 2 & 6 & 8 & 11 & 11 & 22 & 30 \\
\hline Television & 3 & 5 & 8 & & & & 8 \\
\hline Comparing & 4 & 3 & 7 & 1 & 2 & 3 & 10 \\
\hline Underline & 3 & 1 & 4 & 5 & 1 & 6 & 10 \\
\hline Own knowledge & 4 & 0 & 4 & & & & 4 \\
\hline Truncate the text & 2 & 1 & 3 & & & & 3 \\
\hline Teacher & 1 & 2 & 3 & & & & 3 \\
\hline Listening & 0 & 2 & 2 & & & & 2 \\
\hline No answer & 0 & 2 & 2 & & & & 2 \\
\hline Copy & 0 & 1 & 1 & & & & 1 \\
\hline Rework the text & & & & 24 & 21 & 45 & 45 \\
\hline Labels & & & & 8 & 13 & 21 & 21 \\
\hline Summary/introduction & & & & 11 & 5 & 16 & 16 \\
\hline Plan & & & & 8 & 8 & 16 & 16 \\
\hline Diary & & & & 4 & 4 & 8 & 8 \\
\hline Working & & & & 3 & 3 & 2 & 8 \\
\hline Other & & & & 2 & 0 & 2 & 2 \\
\hline Total & 154 & 147 & 301 & 173 & 159 & 332 & 633 \\
\hline
\end{tabular}

In the planning phase most of the students described 3-4 methods, in the evaluation phase they used 4-5 methods (see Table 5). In the implementation phase, pupils highlighted concepts instead of methods. In the evaluation phase, pupils used maps showing the area of the animals' distribution, many drawings about animals spoor as well as relevant information upon which they elaborated and organised for their own use. Pupils used a variety of learning strategies and thought about what they were doing in the evaluation phase, using the diary as an important method for reflection.

Table 5. The number of methods in the planning and evaluation phase.

\begin{tabular}{|c|c|c|c|c|c|c|}
\hline \multirow{2}{*}{$\begin{array}{c}\begin{array}{c}\text { Vee } \\
\text { heuristics }\end{array} \\
\begin{array}{c}\text { Number of meth- } \\
\text { ods }\end{array}\end{array}$} & \multicolumn{3}{|c|}{ Planning phase } & \multicolumn{3}{|c|}{$\begin{array}{c}\text { Evaluation } \\
\text { phase }\end{array}$} \\
\hline & Girl & Boy & Total & Girl & Boy & Total \\
\hline 0 & 0 & 2 & 2 & 1 & 3 & 4 \\
\hline 1 & 0 & 2 & 2 & 0 & 2 & 2 \\
\hline 2 & 18 & 22 & 40 & 8 & 2 & 10 \\
\hline 3 & 36 & 54 & 90 & 33 & 84 & 117 \\
\hline 4 & 64 & 36 & 100 & 52 & 24 & 76 \\
\hline 5 & 30 & 25 & 55 & 55 & 20 & 75 \\
\hline 6 & 6 & 6 & 12 & 24 & 24 & 48 \\
\hline Total & 154 & 147 & 301 & 173 & 159 & 332 \\
\hline
\end{tabular}


Sirpa KÄRKKÄINEN. How Do Animals Spend the Winter? A Finnish Study on the Use of Vee Heuristics in a Biology Unit for Eighth Graders

What are the Main Factual Conclusions which You Have Constructed Out of the Data?

PROBLEMS

OF EDUCATION

IN THE $21^{\text {st }}$ CENTURY

Volume 47, 2012

83

The classification of pupils' knowledge claims in accordance with SOLO-taxonomy, is shown in table 6. Most of the pupils' knowledge claims were relational and at an extended abstract level.

Table 6. The classification of pupils' $(\mathrm{N}=92)$ knowledge claims in the evaluation phase.

\begin{tabular}{|c|c|c|c|c|}
\hline Category & Girl & Boy & Total & $\%$ \\
\hline Pre- and unistructural knowledge & & & 17 & 18.5 \\
\hline Claims which included mistakes & 8 & 7 & 15 & \\
\hline No knowledge claims evaluation & & 2 & 2 & \\
\hline Multistructural & & & 23 & \\
\hline Factual knowledge & 12 & 7 & 19 & \\
\hline Opinion & 0 & 4 & 4 & 15.2 \\
\hline Relational & & & 8 & \\
\hline Explanation & 4 & 4 & 6 & \\
\hline Learning of skills and ecology concepts & 0 & 6 & 35 & 38 \\
\hline Extended abstract level & & & 2 & \\
\hline Evaluation of knowledge & 1 & 1 & 2 & \\
\hline New research question & 0 & 2 & 22 & \\
\hline Discussion & 12 & 10 & 9 & \\
\hline Generalisation & 7 & 2 & 3 & 3.3 \\
\hline Other & & & 2 & \\
\hline Don't remember & 0 & 1 & 100 \\
\hline No answer & 44 & & & \\
\hline Total & & & & \\
\hline
\end{tabular}

Pre- and unistructural knowledge claims are claims which included mistakes. In the evaluation phase, pupils had some mistakes and misconceptions concerning animals' adaptation to winter. Some pupils did not understand the level of torpor and could not remember what animal was in deep torpor. Some knowledge claims were very simple and in the planning phase the pre knowledge of the pupils did not contain explanations or causal relationship.

Multistructural knowledge claims included concepts from which a number of connections may be made but the meta-connections between them were missing. Pupils wrote lots of factual knowledge about animals' winter adaptation which contained figures and very detailed information. Pupils wrote: "The hedgehog hibernates quite well at $-5{ }^{\circ} \mathrm{C}$ with a body temperature of $2.5^{\circ} \mathrm{C}$ and heart rate of 19 beats per minute. Hedgehogs wake up after 4 or 5 hours." and "The vole has ten offspring a year". Pupils also had opinions about other animals. They wrote: "The elk is a good animal for hunting" and "Gulo gulo is a terrible predator".

Relational knowledge claims included concepts which are linked each other and are parts in relation to the whole. Pupils wrote: "Next time I will be able to work better on a new project than this one", "I understood that the lynx is not so small as I had thought" and "By investigation of skulls and their anatomy I found out if the animal was herbivore or predator". 
PROBLEMS

OF EDUCATION

IN THE $21^{\text {st }}$ CENTURY

Volume 47, 2012

Pupils used extended abstract level knowledge claims in connection with concepts, generalised principles and ideas. They wrote: "The ability to become a dormant does not probably play a role in governing the distribution of the mammal", "I learned about inquiry itself and new things about animals. It was wonderful because I was able to told my mother about the hedgehog and its overwintering when she asked.", and "The board distribution of several species of hibernators over many climatic areas, is evidence that large populations of the species do not make use of their physiological ability".

\section{How Worthwhile is the New Knowledge?}

Pupils' descriptions are classified into seven categories. The classification of pupils' evaluation of knowledge claims is shown in table 7. Most of the knowledge claims included positive attitudes to learning and new knowledge.

Table 7. The classification of pupils' $(\mathrm{N}=92)$ value claims in the evaluation phase.

\begin{tabular}{|c|c|c|c|c|}
\hline Category & Girl & Boy & Total & $\%$ \\
\hline Learning for the understanding of ecology & 31 & 25 & 56 & 30 \\
\hline Evaluation of the whole learning process & 25 & 23 & 48 & 26 \\
\hline New knowledge is worthwhile and useful & 28 & 23 & 51 & 27 \\
\hline My opinion become more positive & 12 & 4 & 16 & 9 \\
\hline Knowledge is not worthwhile & 2 & 5 & 7 & 4 \\
\hline No comments & 3 & 3 & 6 & 3 \\
\hline Total & 101 & 83 & 184 & 100 \\
\hline
\end{tabular}

Pupils were able to construct new meaningful knowledge. The knowledge claims which had been made in the evaluation phase were complicated and covered a wide area on the issue. Pupils' new knowledge has been gained in their attempt to understand winter ecology. The activity encouraged problem solving and provided appropriate feedback to Vee heuristics with its ten questions reducing emphasis on learning the facts and increasing emphasis on learning scientific processes. Pupils wrote: "Biology is interesting. I will use biology knowledge in future", "I like biology and feel successful at it","The learning process is enjoyable and satisfying in itself. Now I have a positive attitude towards biology", "I want to use this knowledge; someday this will be useful to me" and "I think that the whole process is important: the planning, implementation and evaluation phase". A few of the knowledge claims showed a negative attitude to knowledge. Pupils wrote: "I think that this project was useless. The knowledge I searched for was useless" and "I will never need this information".

\section{How Worthwhile are Vee Heuristics?}

Pupils thoughts on the use of Vee heuristics are shown in table 8. Pupils' abilities to produce Vee heuristics may vary; some were unfamiliar with it and had difficulties although all of them (with the exception of one pupil) had used it before. Pupils wrote: "I don't know what I am doing. I don't understand the form of Vee heuristics" and "Vee heuristics is different and it required effort and more work than in the other tasks". $35 \%$ of the pupils had positive 
experiences of Vee heuristics: "Vee is an effective strategy because it demands thinking”, "I

preparation. I am better able to identify weakness in my time table" and "Vee is transferable across different tasks".

The Vee heuristic was considered to be new, variable and concise and its use made it possible for pupils to follow their own learning process. $45 \%$ of the pupils had negative thoughts about the Vee heuristic, reflecting confusion and a negative attitude towards the new method. Vee heuristics help pupils to realize what they already know and to gain new knowledge in their attempt to understand winter ecology. The eighth graders were able to plan, monitor and evaluate their own learning process. Some of the pupils were unable to present either a positive or negative attitude towards Vee. $4 \%$ of the pupils did not even answer the evaluation question concerning Vee heuristics as a method in general.. "I am actively participate in my own learning process" and "I construct new meaningful knowledge".

Pupils estimated time requirements and organised materials, finally evaluating their success and identifying learning strategies which would be valuable for the future. Pupils are aware of the learning process but perhaps there is not sufficient guidance about how to work with Vee heuristics. They believed in the value of the task and in their own abilities and commented on how they have dealt with difficulties. (Table 8.)

Table 8. The decription of pupils $(\mathrm{N}=92)$ value claims about the use of Vee heuristics.

\begin{tabular}{|c|c|c|c|c|c|c|}
\hline Description & Girl & $\%$ & Boy & $\%$ & Total & $\%$ \\
\hline Negative & 16 & 36 & 25 & 52 & 41 & 45 \\
\hline Positive & 17 & 39 & 15 & 31 & 32 & 35 \\
\hline No comments & 9 & 20 & 6 & 13 & 15 & 16 \\
\hline Don't know & 2 & 5 & 2 & 4 & 4 & 4 \\
\hline Total & 44 & 100 & 48 & 100 & 92 & 100 \\
\hline
\end{tabular}

\section{Discussion}

Are pupils interested in animals in winter? If so, are they more interested in some ecological topics than in others? Pupils' questions can be a key element in the teaching and learning process in biology. Pupils' focus questions extend their prior knowledge and establish linkages and relationships between existing knowledge and experiences, leading to the construction of new comprehensive conceptions. In the planning phase pupils mainly used focus questions which recall factual information and "why" and "how" questions which need explanations about a process or phenomena. Pupils' focus questions are linked to descriptive ecology (simple descriptions about their observations) and comparative ecology (descriptions of animals and their behaviour). The focus questions of biological activities and process are linked to causal ecology. According to the results of this study, pupils' questions deal with four levels of ecological organisation - individual organisms, populations, communities and ecosystems. In addition, pupils' questions deal with a variety of spatial scales, from the community to that of the whole biosphere. It is important to acknowledge that not all of the focus questions were related to content, thus some pupils have difficulties in making reliable focus questions, a finding which is in accordance with the previous results of Yip (2004, 2009). 
PROBLEMS

OF EDUCATION

IN THE $21^{\text {st }}$ CENTURY

Volume 47,2012

86

Value claims are important in emphasizing the value of knowledge. During the learning process pupils'attitudes to learning biology change. The same results were apparent in Jamaican eighth graders who participated in the study of Ugwu and Soyibo (2004) even though it was not in the context of biology education. Vee heuristics and inquiry based learning is a strategy aimed to enhance pupils' interest in biology, which is important (see Prokop et al., 2007, Uitto et al., 2006). Winter ecology is relevant to pupils' lives and many of them will use the things learned in concrete situations. (see also Patrick \& Tunnicliffe, 2011; Lindemann-Matthies, 2006). The pupils appreciated this and considered the knowledge gained as being useful in the future, even though in the beginning of the learning process, they didn't understand why they should use their time, resources and their own lives to solve these problems.

The pre-, inter-and post-instructional evaluation of pupils' Vee heuristics here, shows evidence of an increase of concepts in the understanding of winter ecology. The content areas in which the most significant understanding occurred, were the biotic elements of winter acclimatization. In the implementation phase pupils used mainly a single organism and named single species, especially owls. In the evaluation phase, identification of another organism followed, describing its adaptation to winter. Inquiry-based study of a single organism has, in other studies (see Magntorn \& Helldén, 2007a; 2007b), been shown to be highly motivating for the students. The study of Margo et al. (2001) as well as Magntorn and Hellden (2007a) have previously shown that students lose interest if they are not familiar with the organism. In this study, all of the birds and mammals are local animals. For example, in the evaluation phase pupils used the concept of owls and its subconcept, species Bubo bubo, Asio otus, Aegolius funereus as well as the concept of mammals and its subconcepts mouse, vole, bear, wolf and lynx. This means that they linked single organisms to systemic thinking and used concepts which indentified prey - the predatory system.

This study provides useful information about the gaps in pupils' conceptual and methodological basis and the types of misconceptions pupils are likely to have about the subject "animals in winter". Especially in the planning phase, pupils' Vee heuristic contained a lot of everyday experiences and misconceptions concerning subjects such as hibernation and animals' nutrition in winter. The biology teacher needs to be aware that such misconceptions exist in the minds of pupils and should act upon them (see Patrick and Tunnicliffe, 2011). Reasoning about the functions of the animal in relation to the whole ecosystem was largely absent in the planning phase. This was not surprising and is supported by other studies (see e.g. Magntorn \& Helldén, 2007a). In this study, pupils highlighted biotic elements in the winter ecosystem although abiotic elements are also important.

The results of this study provide support for the previously perceived implications for the use of Vee heuristics (e.g. Ugwu \& Soyibo, 2004; Vanhear \& Pace, 2008; Åhlber \& Ahoranta, 2002; Åhlberg et al., 2005). Using Vee heuristics, eighth-grade pupils are also able to plan, monitor and evaluate their own learning activities. The ten questions of Vee directed pupils towards observing their own learning, which gave them the feeling of independence. Vee heuristics also help pupils to understand the cognitive and affective elements that interplay in learning. The results cannot be generalized, but we hope that this study encourages other teachers to use Vee heuristics in biology learning at the secondary school level.

According to this study, the local Science museum can help pupils to observe ecosystems if the possibilities of studying the ecosystem outdoors is not possible. It is especially easy to see the anatomy of animals and their features (e.g. skull, fur, and colour in winter) in the Science museum. In their previous research, Magntorn and Helldén (2007a) found that the recognition of species (and taxonomy) help students read about nature, if naming is related to the functional level. Results of this study as well as previous studies of Falk and Storksdieck (2005) and Tunnicliffe and Later-Veer de Beer (2002) show that most of the eighth-grade pupils combined structural and functional aspects in winter ecology because they observed, for example, skulls 
and teeth which are easily seen in a museum. In this study, results show that conservation issues are also important for students. This is not in agreement with the previous study of Tunnicliffe (1999).

When teaching, biology teachers should be aware of various meanings of adaptation. In the evaluation phase, pupils' mainly used concepts concerning physiological or behavioural adaptation to winter. According to Ashelford (2002) it is also important to distinguish adaptation as a process of long-term evolutionary change. In this study, few eighth graders asked questions concerning evolutionary adaptation (for example the hare's white coat) or explained adaptation with evolution. In the Finnish national curriculum (2004) evolutionary adaptation is included in ninth grade biology, thus the eighth graders had no knowledge about the mechanism of evolutionary adaptation or evolution in general.

In this study, eighth graders refer to adaptation as being a process of short-term change. This usually involves a change in physiology, behaviour or development, made in direct response to a change in external conditions. Many birds migrate south in winter in response to cold weather or the shortening length of the day. Many small mammals are nocturnal as the lack of light renders them harder to detect. These responses to changes in external circumstances are inherited and as such are adaptations, in the same sense as the white coat of the polar bear is an adaptation to its environment. They are simply more flexible and in many ways more sophisticated, examples of evolutionary adaptations. This is a difficult distinction to make. In our curricula the mechanism of evolution is not included in grade 8 , however we can reinforce the idea of why some organism undergoes seasonal or diurnal changes and why some apparently do not.

Secondary school students described a feature of an organism that aids its ability to survive and reproduce in its natural environment. Their examples included morphological features of organism such as coat colouring. Adaptations can also be behavioural or physiological such as hibernation. Secondary school students also described adaptation as a process in which an organism makes and appropriate response to a change in the environment, for example many birds adapt to seasonal changes in climate by migrating to warmer habitats in winter. These responses relate to short term changes in behaviour, physiology or development. However, in biology education it is also important to teach and learn adaptation as a process of change which also refers to long-term evolutionary changes.

Results in this study show that although pupils draw animals' distribution in their maps, the relationships between climate, geography and physiological mechanisms are complicated (see Ashelford, 2002). Physiology helps to explain how animals can live where they do but rarely explains the exact limits of their distribution. Factors which limit the occurrence of the species would be competition, habitat-selection, diet and behavioural mechanisms, thus the ability to hibernate does not appear to be a distributional determinant. Pupils also used the concept "endangered animals" in the planning and evaluation phase of this study. Wolves have been listed as an endangered species in Finland and are rarely observed in nature. It may just be that the lack of actual experiences with those big mammals could be one of the reasons why pupils are interested in them. Perhaps it tells us something about positive attitudes towards large carnivores or that pupils use adaptation to explain the distribution and relative abundance of organisms in habitat.

\section{Conclusions}

On examining Vee heuristics, one notes the difference in the answers on each side. In the evaluation phase, pupils used the concept "adaptation to winter", thus in the planning phase most of the pupils used the concept "overwintering and hibernation". In the evaluation phase, pupils also used concepts of big predators and small rodents. The size of the animal is important 
PROBLEMS

OF EDUCATION

IN THE $21^{\text {st }}$ CENTURY

Volume 47, 2012

in its ability to adaptat to winter. Because of their high metabolic rates, some small mammals and birds are faced with an acute need for a continual supply of food and water. The ability to drastically lower their metabolism conserves their food and water. One of the most important factors in the control of heat loss is the barrier between the core of the animal and the external environment.

Vee heuristics included three mental processes involved in learning; cognition, conation and affectation. Data collected in this research reveals that each pupil processes incoming information differently and therefore it is very unrealistic to expect all pupils to respond to whatever happens in class in approximately the same way. Results confirm that for a pupil "to take an interest in learning" the teacher must be aware of the pupil's own preferred way of learning in order to address his/her needs and enhance his/her learning experience. Vee heuristics were used with different groups from which, although rather small in size, some conclusions could be made. The right side of the Vee heuristics showed an increasing number of skills and concepts, which used as an assessment tool, describe changes in pupils' conceptual understanding.

The Vee heuristic lent itself beautifully to a process of reflection and action in which pupils' internal language became visually overt and explicit. In this way pupils are taught to think aloud, reflect on what is going on in their heads and decide how they can proceed to act and develop it. By constructing Vee for the focus question under study, at a glance pupils clearly conveyed "what they already know", thus providing educators with the opportunity to build upon it. The learning programme was very effective in allowing both the teacher and the learner to easily see what prior knowledge was present, what new knowledge had been constructed and how this was integrated and elaborated within the pre-existing cognitive structure. Vee heuristics provide the teacher and the learner with a clear picture of how the learner responds to and acts upon incoming information. This metacognitive teaching strategy shifts the control from the teacher to the learner, resulting in learners becoming the agents of their own learning, since they are actively participating in their own learning process. Moreover, the learner exhibits how he/she plans to learn more. This is very important in order for the teacher to be able to collaboratively build a learning programme which would be relevant to the learner's way of responding to new information and so prove to be truly motivating and meaningful.

Analysis of the ten questions in the planning, implementation and evaluation phase was done by triangulating the data to expand the richness of the answers. Thus in this study, Vee heuristics are analysed to complete the validity of the research and to prove that pupils have different ways of representing their conceptions of animals in winter. In this study it is also evaluated changes in the average numbers of concepts. Some of the pupils' concepts did not fit well within the concept categories and categorisation of pupils' questions was not a simple task. For example, pupils' focus questions were analysed with taxonomy. Taxonomic classification of focus questions formalizes hierarchical arrangement of species, genus, family, order and class but some pupils' concepts did not fit well within taxonomy. The question has to be determined with reference to the specific context in which the question is asked.

\section{References}

Ashelford, S. (2002). Adaptation - a question of definitions? School Science Review, 83 (304), 97-102.

Biggs, J. F., \& Collis, K. F. (1982). Evaluating the quality of learning. The SOLO taxonomy (Structure of the Observed Learning Out-Come). New York: Academic Press.

Deci, E. L., Koestner, R., \& Ryan, R. M. (2001). Extrinsic rewards and intrinsic motivation in education: reconsidered once again. Review of Educational Research, 711-27.

Falk, J. H., \& Dierking, L. D. (2010). Learning from museums: Visitor experiences and the making of meaning. American Association for State and Local History Book Series. Walnut Creek: AltaMira Press. 
Falk, J., \& Storksdieck, M. (2005). Using the contextual model of learning to understand visitor learning from a science center exhibition. Science Education, 89 (5), 744-778.

Finn, H., Maxwell, M., \& Calver, M. (2002). Why does experimentation matter in teaching ecology? Journal of Biological Education, 36 (4), 158-162.

Gehring, K. M., \& Eastman, D. A. (2008). Information fluency for undergraduate biology majors: applications of inquiry-based learning in a developmental biology course. Life Science Education, 7, 54-63.

Grotzer, T. A., \& Bell Basca, B. (2003). How does grasping the underlying causal structures of ecosystems impact students understanding? Journal of Biological Education, 38 (1), 16-29.

Hamilton-Ekeke, J. T. (2007). Relative effectiveness of expository and field trip methods of teaching on students' achievement in ecology. International Journal of Science Education, 15, (83), 18691889.

Krombass, A., \& Harms, U. (2008). Acquiring knowledge about biodiversity in a museum - are worksheets effective. Journal of Biological Education, 42 (4), 157-163.

Lin, C. Y., \& Hu, R. (2003). Students' understanding of energy flow and matter cycling in the context of food chain, photosynthesis and respiration. International Journal of Science Education, 25 (12), 1529-1544.

Lindemann-Matthies, P. (2006). Investigating nature on the way to school: responses to an educational programme by teachers and their pupils. International Journal of Science Education, 28, 895918.

Magntorn, O., \& Helldén, G. (2007a). Reading nature from a "bottom-up" perspective. Journal of Biological Education, 41 (2), 68-75.

Magntorn, O., \& Helldén, G. (2007b). Reading new environments: students' ability to generalise their understanding between different ecosystems. International Journal of Science Education, 1, (15), 67-100.

Mintzes, J. J., Wandersee, H. H., \& Novak, J. D. (2001). Assessing understanding in biology. Journal of Biological Education, 35 (3), 118-124.

McLaren, I. A. M., \& Webber, D. (2009). Writing Right: Enhancing student engagement and performance in an ecology course. International Journal of Environmental \& Science Education, 4 (4), 365 380.

National Board of Education, (2004). Perusopetuksen opetussuunnitelman perusteet 2004. (Basics for Comprehensive School curriculum. Available: http://www.poh.fi/info/ops/pop_web.pdf $(12 / 09 / 2012)$.

Novak, J. D., Gowin, B., \& Johansen, G. T. (1983). The use of concept mapping and knowledge Vee mapping with junior high school science students. Science Education, 67 (5), 625-645.

Novak, J., \& Gowin, B. (1984). Learning how to learn. London: Cambridge University Press.

Novak, J. (2002). Meaningful learning: The essential factor for conceptual change in limited or inappropriate propositional hierarchies leading to empowerments of learners. Science Education, 84 (4), 548-571.

Patrick, P., \& Tunnicliffe, S. (2011). What plats and animals do early childhood and primary students' name? Where do they see them? Journal of Science Education and Technology, 20, 630-642.

Patton, M. Q. (2001). Qualitative evaluation and research methods (Third edition). Newbury Park: Sage.

Pintrich, P. R., Marx, R. W., \& Boyle, R. A. (1993). Beyond cold conceptual change: the role of motivational beliefs and classroom contextual factors in the process of conceptual change. Review of Educational Research, 62, 167-199.

Prokop, P., Prokop, M., Tunnicliffe, S. D., \& Diran, D. (2007). Children's ideas of animals' internal structures. Journal of Biological Education, 41 (2), 62-67.

Sander, E., Jelemenska, P., \& Kattmann, U. (2006). Towards a better understanding of ecology. Journal of Biological Education, 40 (3), 119-123.

Tsai, C. C., Liu, E. Z. F., Lin, S. S. J., \& Yuan, S. M. (2001). A networked peer assessment system based on a Vee heuristics. Innovations in Education and Teaching International, 38, 220-230.

Tunnicliffe, S. (1996). The relationship between pupil's ages and the content of conversations generated at three types of animal exhibits. Research Science Education, 26 (4), 461-480.

Tunnicliffe, S. D., \& Laterveer-de Beer, M. (2002). An interactive exhibition about animals' skeletons: did the visitors learn any zoology? Journal of Biological Education, 36 (3), 130-134. 
PROBLEMS

OF EDUCATION

IN THE $21^{\text {st }}$ CENTURY

Volume 47, 2012

90

Tunnicliffe, S. D., \& Reiss, M. J. (1999). Building a model of environment: how do children see animals. Journal of Biological Education, 33 (4), 142-148.

Uitto, A., Juuti, K., Lavonen, J., \& Meisalo, V. (2006). Students' interest in biology and their out-ofschool experiences. Journal of Biological Education, 40 (3), 124-129.

Ugwu, O., \& Soyibo, K. (2004). The effects of concept and vee mappings under three learning modes on Jamaican eighth graders' knowledge of nutrition and plant reproduction. Research in Science \& Technological Education, 22 (1), 41-58.

Vanhear, J., \& Pace, P. J. (2008). Integrating knowledge, feelings and action: using Vee heuristics and concept mapping in education for sustainable development. Journal of Teacher Education for Sustainability, 10, 42-55.

Yip, D. Y. (2004). Questioning skills for conceptual change in science instruction. Journal of Biological Education, 38 (2), 76-83.

Yip, C. W. (2009). Causal and teleological explanations in biology. Journal of Biological Education, 43 (4), 149-151.

Wilde, M., \& Urhahne, D. (2008). Museum learning: a study of motivation and learning achievement. Journal of Biological Education, 42 (2), 78-83.

Åhlberg, M. (1998). Education for Sustainability, good environment and good life. In Åhlberg M. \& Leal Filho, W. (Eds.) Environmental education for sustainability: Good environment, good life. Frankfurt am Main: Peter Lang, 25-43.

Åhlberg, M., \& Ahoranta, V. (2002). Two improved educational theory based tools to monitor and promote quality of geographical education and learning. International Research in Geographical and Environmental Education, 11 (2), 119-137.

Åhlberg, M., Äänismaa, P., \& Dillon, P. (2005). Education for sustainable living: integrating theory, practice, design, and development. Scandinavian Journal of Educational Research, 49 (2), $167-$ 186.

Advised by Tuula Keinonen, University of Eastern Finland, Joensuu, Finland

Received: September 03, 2012

Accepted: September 25, 2012

Sirpa Kärkkäinen

Dr, Senior Lecturer, University of Eastern Finland, School of Applied Educational Science and Teacher Education, Box 111, 80101 Joensuu, Finland.

E-mail: sirpa.a.karkkainen@uef.fi

Website: http://uef.fi 